\title{
Assessment Principles for the Mechanical Behavior of Clay Soils
}

\author{
NIKOLAOS ALAMANIS ${ }^{1}$, PHILOTHEOS LOKKAS ${ }^{2}$, THEODOROS CHRYSANIDIS ${ }^{3}$, \\ DIMITRIOS CHRISTODOULOU ${ }^{4}$, EVANGELOS PASCHALIS ${ }^{5}$ \\ ${ }^{1}$ Department of Agriculture - Agrotechnology, University of Thessaly, Larissa, GREECE \\ ${ }^{2}$ University of Thessaly, Larissa, GREECE \\ ${ }^{3}$ Department of Environmental Engineering, International Hellenic University, Thessaloniki, GREECE \\ ${ }^{4}$ Environmental Department, University of Thessaly, Larissa, GREECE \\ ${ }^{5}$ Department of Forestry, Wood Sciences and Design, University of Thessaly, Karditsa, GREECE
}

\begin{abstract}
The factors that determine the geotechnical behavior of soils are mainly their composition, the size of their grains and their moisture content. The design of a soil structure or foundation project must ensure the shear adequacy of the soil in all phases of construction and throughout the life of the project. However, the shear strength, in general, of the soil is not "constant" but depends on key external factors such as the prehistory of loads, the time and succession of load states, the overpressure of the pore water as well as other factors such as relative density, or any preload, the pressure field, the rate of change of the intensive state, etc. The influence of the deformations as well as the change of the intensive state during the sampling should not be ignored. Unlike other materials, in clay materials the determination of shear strength and its interpretation is a very complex problem. The aim of this article is to search for the mechanical behavior of clay soils (lignite, kaolinite, marl) as shown by the laboratory illustration related with the problems on shear strength of materials, based on the results of experimental research.
\end{abstract}

Key-Words: - Clay minerals, clay structure, shear strength, mechanical behavior, triaxial tests, stress-strain analysis, consolidation.

Received: January 17, 2021. Revised: July 18, 2021. Accepted: July 26, 2021. Published: August 4, 2021.

\section{Introduction}

The design related on the shear behavior of a soil material is of particular interest because it has a direct impact on practical problems of bearing capacity [1], stability of slopes and embankments $[2,3,4,5]$ as well as permanent seismic movements of slopes $[6,7,8]$. The presence of clay soils in the geological structure associated with the construction of a technical project, in most cases adversely affects its stability. Apart from areas where extensive research has been done in the past, or where there is considerable local experience with a particular soil type (eg London clay) where practical design parameters have already been identified, there is no general approach to the problem of direct or indirect measurement of stability, with some degree of accuracy. One of the main reasons is that clay is a compressible material. In fact, when there is a tablewater, then the load is slowly transferred to the solid frame of the soil mass resulting in significant subsidence. Coulomb's long-held view that shear strength is related with the normal stress on the shear plane, was supplemented by Terzaghi in 1936 [9] by the formulation of the principle of effective stresses. Through the principle of active stresses, we still quantitatively estimate the magnitude of the shear strength for the clay materials. The necessary relations that link the change in pore pressure (hence the active stresses) with the change of an intensive state, were given by Skempton (1954) [10] with the known pore pressure parameters of soil A and B. The correlation of an intensive situation changes with the development of pores' water pressure, and, of course, the strength through the parameter of pores' pressure, was a serious step for the interpretation of the soil behavior in many problems of Soil Engineering and Foundations. (Alamanis - Mantzouranis, 1987) [11]. Each specific problem of strength in Geotechnics requires, for its solution, precise data on soil properties, the problem's geometry, and the sequence of load states, which are then utilized with a scientifically accepted methodology of analysis (Ladd, 1971) [12]. Typical examples of problems whose analysis is based on assumptions and results of total and / or effective stresses are the strength of clay embankments $[13,14]$, the laying of road surfaces on clay soils $[15,16]$, the behavior of clay cores in the construction of dams, erosion on clay slopes of open-flow channels [17,18], erosion of fine-grained bottoms of streams and rivers $[19,20]$, bearing capacity of clay pavements, subsidence of clayey soils, the vulnerability of thin-walled buildings $[21,22,23]$ as well as the shear strength of clay slopes. The most effective way to express the strength of clay comes from the qualitative interpretation of the stress-strain diagrams (s-e). The 
target of this study is the mechanical strength of clay soils such as lignite, marl and kaolinite and compare their shear strength with that of clay, through stressstrain diagrams that emerged after experimental investigation.

\section{Previous Experimental and Analytical Studies}

In the present paper, clay soils are presented and discussed. Articles [1-8] attempted to determine the effect of mechanical behavior of soil and clay materials on works, designs and constructions related to bearing capacity along with the stability of slopes and embankments. Their study reinforced the theoretical background of this research together with the classic publications of Terzaghi [9] and Scempton [10] who were the pioneers on the behavior of clays through the theory of active stresses and water resource pressure. AlamanisMantzouranis [11] investigated the shear behavior of Ptolemaida lignites via Consolidated Undrained (CU) tests, which, afterwards, they were compared with the corresponding tests of Ladd clays [12], who, in his historical work, presented new procedures for design and stability of soft clays [48]. Papageorgiou [13,16] Tsiknas et al., [14] Mouratidis et al. [15] presented construction of pavements and laying of road surfaces in loose soils while at the same time proposing measures to strengthen them. Farsirotou et al. [17-18-19-20] also studied, among others, the erosion of clayey slopes of open-flow channels as well as the erosion of the bottom on fine-grained soils of streams and rivers, while Droudakis et al., [21], Anagnostopoulos et al., [22] proposed methods of reinforcement the strength of sandy and loamy soils. Alamanis et al. [23] presented furthermore ways and methods of reinforcing loose soils, whether the soil behaves as a building material (damsembankments) or as a load receiver (foundation of structures). Then, for the purpose of this research, works were selected, the conclusions of which were used to compare the mechanical properties of related clay materials with that of clay, through stress-strain diagrams that emerged after experimental investigation as already mentioned. Kalteziotis et al. [24] investigated the factors affecting the residual shear strength of marls while Tsirampidis et al. [25] investigated the physical and chemical characteristics of Marga Heraklion. Barth, et al. [27] and Pettijohn [28] classified margarine sediments based on the percentage of calcium carbonate. Gioka [29] in her dissertation presented a geochemical study of sediments of the Cretan basins while PrassaXirouchaki [30] dealt with the structure of kaolinite as an aluminosilicate mineral. E.T Brown [34] first published the structure and synthetic formula of lignite at the University of Melbourne in his research on Morwell lignite in Australia, followed by Trollope et al. who studied the mechanical behavior of the Australian brown coal [49]. Argyraki [36] in her notes in the Geology department of the University of Athens presents the structure of clay minerals while (Kotrotsiou-Frantzeskaki) [38] emphasize in their dissertation that the behavior of clay depends on various secondary factors, such as temperature as well as the rate of increase of stresses and deformations. Koninis et al. [39] presented -among other things- triaxial CU tests in Marly lands from Mavropigi of Kozani, carried out in the Soil Engineering Laboratory of the Aristoteles University of Thessaloniki. At the same time, they point out that in geotechnical design the stress of pre-consolidation is considered one of the most important parameters and represents a yield stress of soil, which distinguishes the elastic from its plastic behavior. I. Lazaridis [40] presented eight triaxial CU tests in the Marly soils of the Isthmus of Corinth, carried out at the National Technical University of Athens' Laboratory. I. Kourelis [41] performed triaxial tests on kaolinite while N. Alamanis [42] in a series of simulations compared the experimental curves of stresses-strain diagrams of isotropically fixed kaolinite specimens (from the dissertation of I. Zervogiannis [43]) with those resulted from the application of SP5 software [44] that strictly follows the hyperbolic law of Duncan. Professor A. Anagnostopoulos studied the soil-technical behavior of the Megalopolis lignites [45], while A. Prousanidou [46] the mechanical behavior of Lamia's clay. Finally, Milaković et al. [47] studied the stiff clay of Zagreb and presented its mechanical behavior with triaxial undrained tests. The comparison of results between the shear behavior of the clay soils (lignite, kaolinite, marl) and those of clay [48], lead to useful conclusions mainly, through stress-strain diagrams. A number of useful conclusions are also furthermore derived, apart from those mentioned in the literature.

\section{Methodology}

The research methodology of this work is based on three stages:

a) structural presentation of the aforementioned clay minerals,

b) presentation of the tests performed on the specimens of the above materials,

c) presentation of results obtained from the experimental investigation.

d) evaluation of the mechanical behavior of clay minerals and comparison with that of clay through stress-strain diagrams, and

e) drawing important conclusions. 


\subsection{Presentation of the Structure and} Composition of Clay Minerals (MargaKaolinite-Lignite and Clay)

\subsubsection{Marga}

Marga is a sedimentary formation that chemically and minerally varies between limestone and clay. The neogene marly formations are widely distributed in the Greek territory and present great interest from a geotechnical point of view, especially for road works. (Kalteziotis, Tsiabaos, 2005). [24] The silt is the main grain size of the non - carbonate elements and varied from 34 to $64 \%$. The textural classification of the SSDS soil samples were mainly silty-clay loams with a moisture level capacity of 30$40 \%$. The prevailing minerals on a variety of samples, being on increasing shortage, were calcite (31-59\%), clay minerals (20-34\%) and quartz (1220\%) (Tsirampidis - Papaliagkas, 2001). [25]

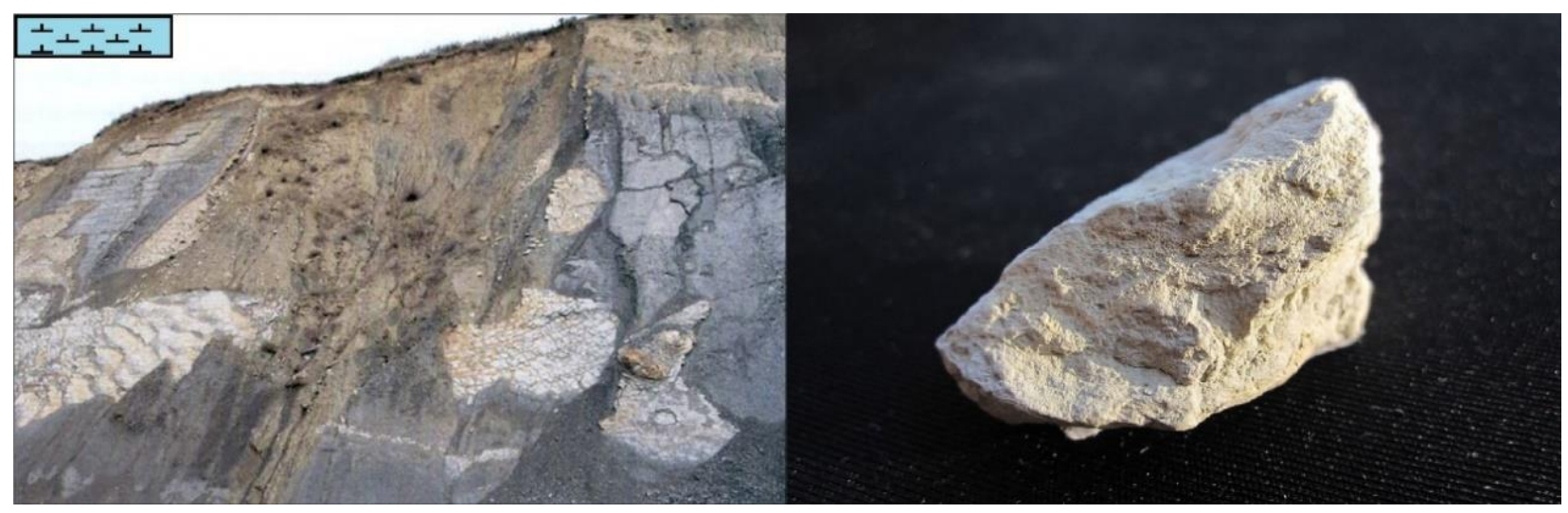

Fig.1: Marga Formations (Stratigraphy) [26]

The chemical composition of a typical marga is usually calcium carbonate, $74 \%$, clay, $22 \%$ and various impurities (quartz, mica, pyrite, etc.), $4 \%$. Between marls and limestones, depending on their carbonate content, many types of rocks can be distinguished, with different chemical composition, such as calcareous marl, margarite limestone, clay marl, dolomitic marl, etc. Generally, when the calcium carbonate content of the clay is greater than $60 \%$ then the sediment is characterized as marl. The deposits of marls can be of either biogenic or chemical origin, as in the case of limestones, while their sedimentation can have taken place in shallow or deep seas or even lakes. Therefore, they can be accordingly distinguished in shallow seas marls, deep seas and lake marls. According to the classification of Barth et al. (1939) and Pettijohn (1975) the sediments between clay and limestone are divided into: clay, marley clay, clay marl, claey marl, marl, limestone marl, limey marl, marly limestone and limestone (Table 1).

Table 1. Classification of margarine sediments based on the percentage of calcium carbonate (Barth et al., 1939; Pettijohn, 1975), (Gioka, 2014). [27], [28], [29]

Clay $(\%)$

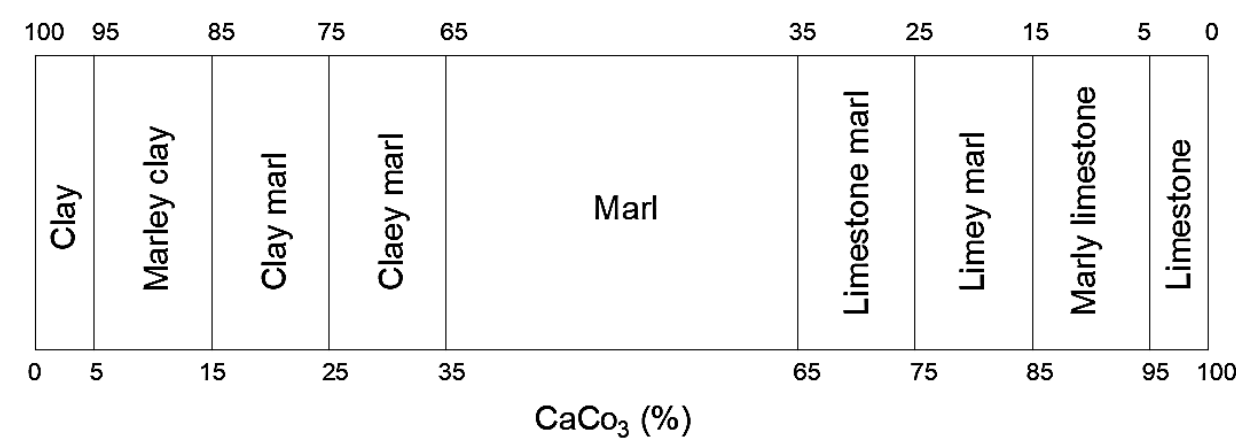

\subsubsection{Kaolinite}

Kaolinite, $\mathrm{Al}_{2} \mathrm{O}_{3} \cdot 2 \mathrm{SiO}_{2} \cdot 2 \mathrm{H}_{2} \mathrm{O}$, is an aluminosilicate mineral, named after the Chinese province of Cauling. The rock, consisting mainly of the mineral kaolinite, is called kaolin. Kaolin is the main ingredient in porcelain. Kaolinite belongs to the group of clay minerals, with a structure of 1:1, i.e. a sheet of silicon tetrahedra is alternated with a sheet 
of aluminum octahedron. The octahedral positions in the octahedral layer are occupied by $\mathrm{Al}_{3}+$ ions (gibbsite layer). Substitutions are limited. In the octahedral layer $\mathrm{Fe}_{3}+$ ions may in some cases replace $\mathrm{Al}_{3}+$ ions, while in the tetrahedral layer there may be only a limited substitution of $\mathrm{Si}_{4}+$ by $\mathrm{Al}_{3}+$. For the kaolinite the chemical formula is $\mathrm{Al}_{2} \mathrm{Si}_{2} \mathrm{O}_{5}(\mathrm{OH})_{4}$. Due to the limited substitution in the kaolinite structure, the total load is minimal.

Kaolinite has limited cation exchange capacity (CEC). The building blocks (sheets) are joined to other sheets by weak Van der Waals forces. Due to these weak forces, the sludges are soft and easily degraded. Kaolinite is characterized by white colour, fine-grained texture, easy dispersion, chemical inertness and low production costs. Coarse-grained kaolin is used as a filler, while fine-grained is used as a coating material. Kaolin is a raw material in ceramics, porcelain, sanitary ware, in the cement industry, in refractory bricks, in the paper industry, in the rubber and plastics industry.

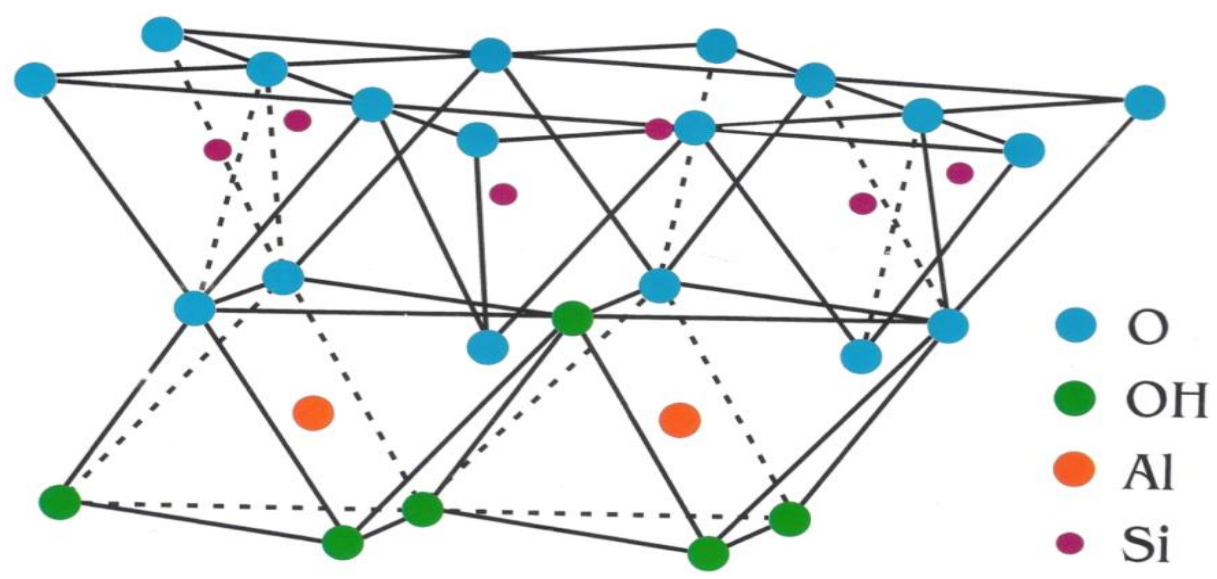

Fig.2: Structure of kaolinite [30]
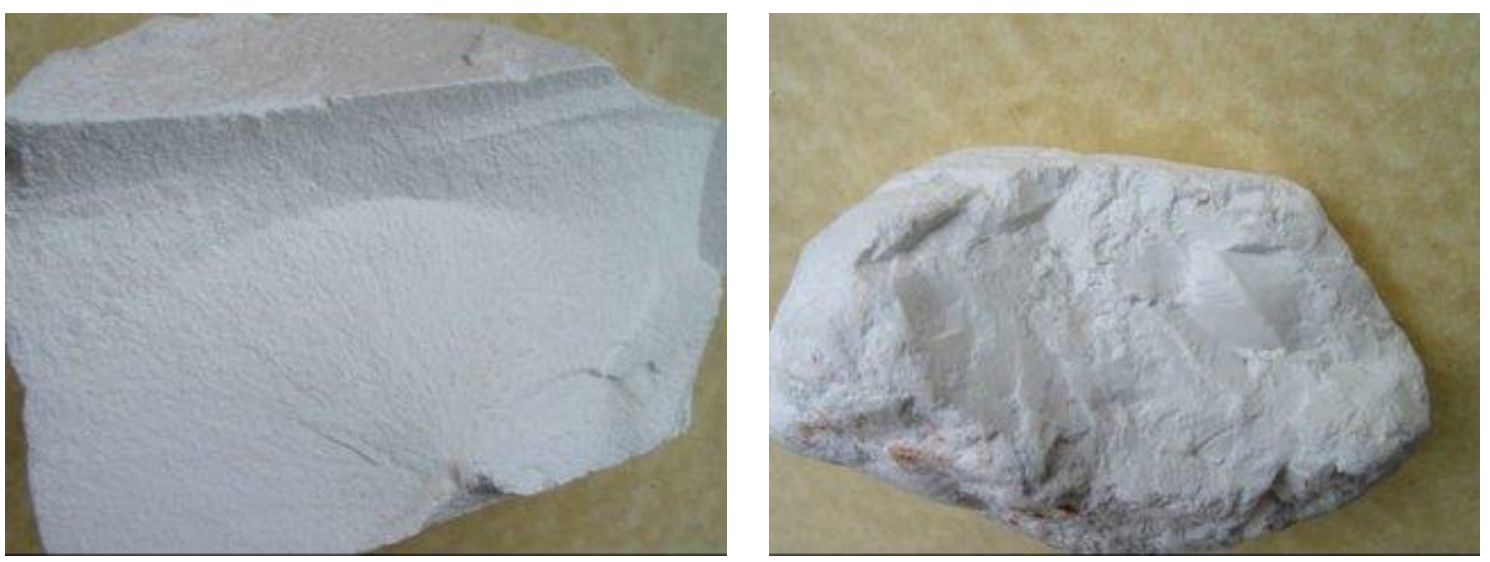

Fig.3: Kaolin Apple [31]

\subsubsection{Lignite}

Lignite, also called coal, is a rock having the carbon (50\% to $70 \%$ ) as its main element and presents an organic origin. It also contains hydrogen, oxygen, water and nitrogen. It is actually the result of carbonization, coming basically from plant organisms, and its calorific value is particularly important. It is mainly used in steam power plants to generate electricity. From the above, the importance of the shear strength becomes obvious, since, as it is known, the economy of the exploitation of open type mines is significantly affected by the stability of the excavated slopes, which is a significant factor for the whole exploitation process.
Its color is brown-black and contains $35-65 \%$ moisture. Graphite, which is pure carbon, has a structure in "layers" which are actually carbon atoms arranged in normal hexagons accumulated in parallel and in a normal manner.

Due to the relatively large distance of the overlapping layers, they are weakly connected to each other, which is why graphite particles are plateshaped, similar to clay particles. In fact, the higher the grade of a carbon, the lower the aliphatic components while the structure is more similar to the inorganic clay (see Figure 6). In these clays the plate particles are oriented parallel to each other, forming 


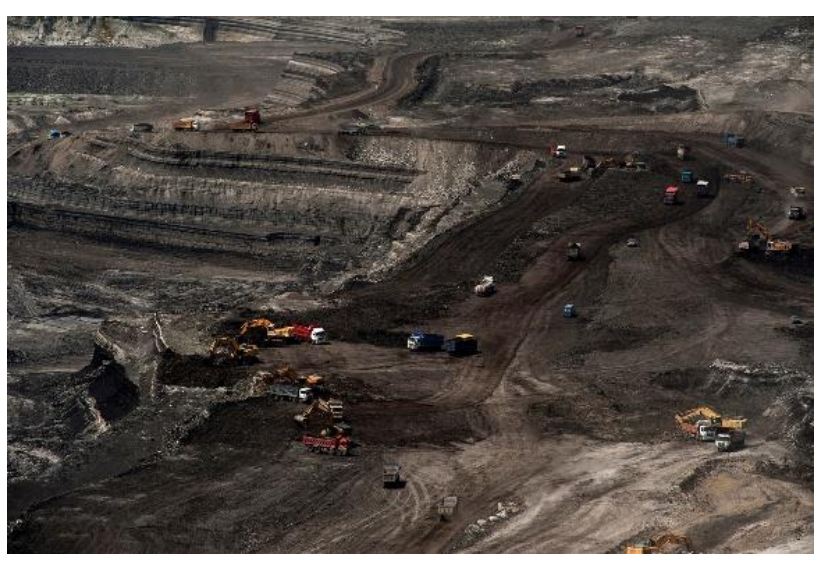

Fig.4: Lignite mine [32]

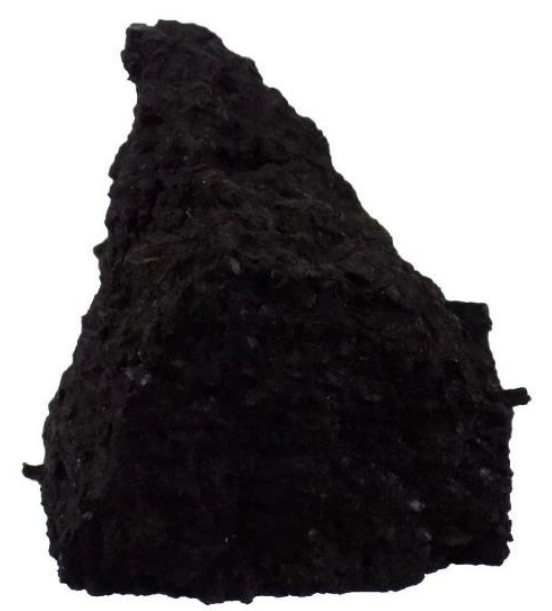

Fig.5: Lignite rock [33]

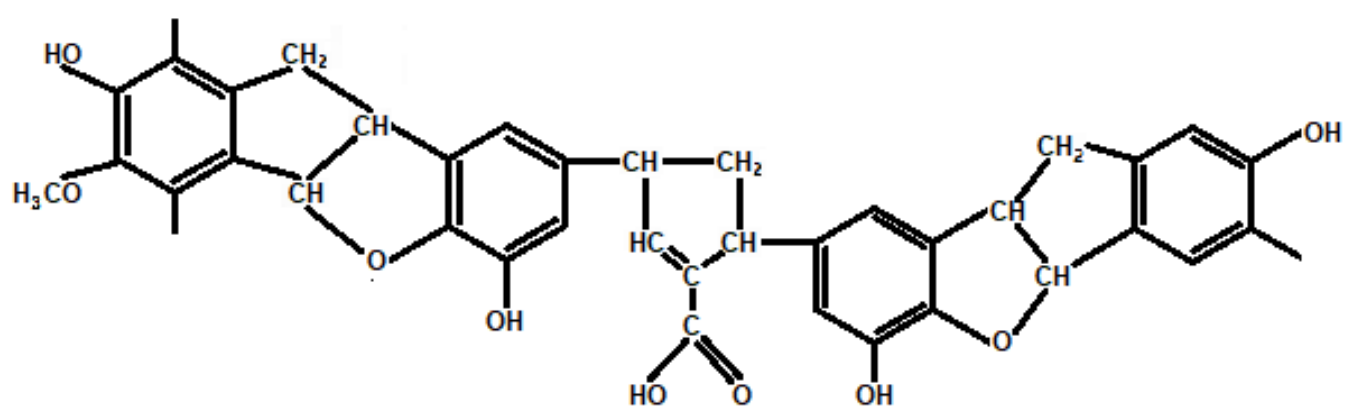

Fig.6: Proposed structural formula of Brown lignite (1963). (Coal Research, C.S.I.R.O., 1959). [34]

\subsubsection{Clay}

It is a very fine-grained soil, colloidal in shape. The shape of the clay particles, in contrast to the sludge and sand is flattened and elongated. The maximum dimension of the particles is $0.008 \mathrm{~mm}$. The inorganic and organic colloidal phase of clay has adsorption capacity in various anions and cations mainly $\mathrm{H}+, \mathrm{Ca}_{2}+$ and $\mathrm{Na}+$, found in water. The swelling of the clay in the presence of water is due to the attraction of $\mathrm{H}+$ ions, while the ability of stabilizing is due to the attraction of calcium or sodium ions. Clay consists of secondary minerals (montmorillonite, kaolinite) derived from chemical decomposition of primary minerals. The majority of clay soils that contain montmorillonite are the most problematic due to their unstable structure (threelayer formation of silicate tetrahedra, clay octahedra) and show intense swelling and shrinkage along with a high plasticity. The least problematic soils are those that contain kaolinite.

Their structure is very stable (bilayer formation of silicate tetrahedra, clay octahedra) with the result that their swelling, shrinkage and plasticity are much less than those containing montmorillonite. Soil fertility depends on the clay content, and productivity on the balanced distribution of the three mechanical soil fractions (sand, silt, clay) along with their mineral composition. Generally, a clay material has a colloidal texture, a great ability to retain moisture and therefore to swell. From the above fractions, clay is the active mineral component of the soil. The determination of $\mathrm{CaCO}_{3}$ found in sand, silt and clay, is necessary for the study of soils.

It should be emphasized that the term clay is not unambiguous. It can mean either a fraction of a certain grain size (clay fraction) or a sedimentary rock with a certain percentage of clay fraction. The clay fraction is usually characterized by the material which consists of grains, with a diameter less than 2 microns, i.e. $0.002 \mathrm{~mm}$. As it results from the classification of soils, clay soils are the most finegrained soil. The most important factors influencing the mechanical behaviour of clay are: water content, chemical composition of the grains, soil texture and soil prehistory. The behaviour of clay varies according to secondary parameters, like the temperature and/or the increase rate of stresses and deformations (Kotrotsiou-Frantzeskaki, 2011). [38] 

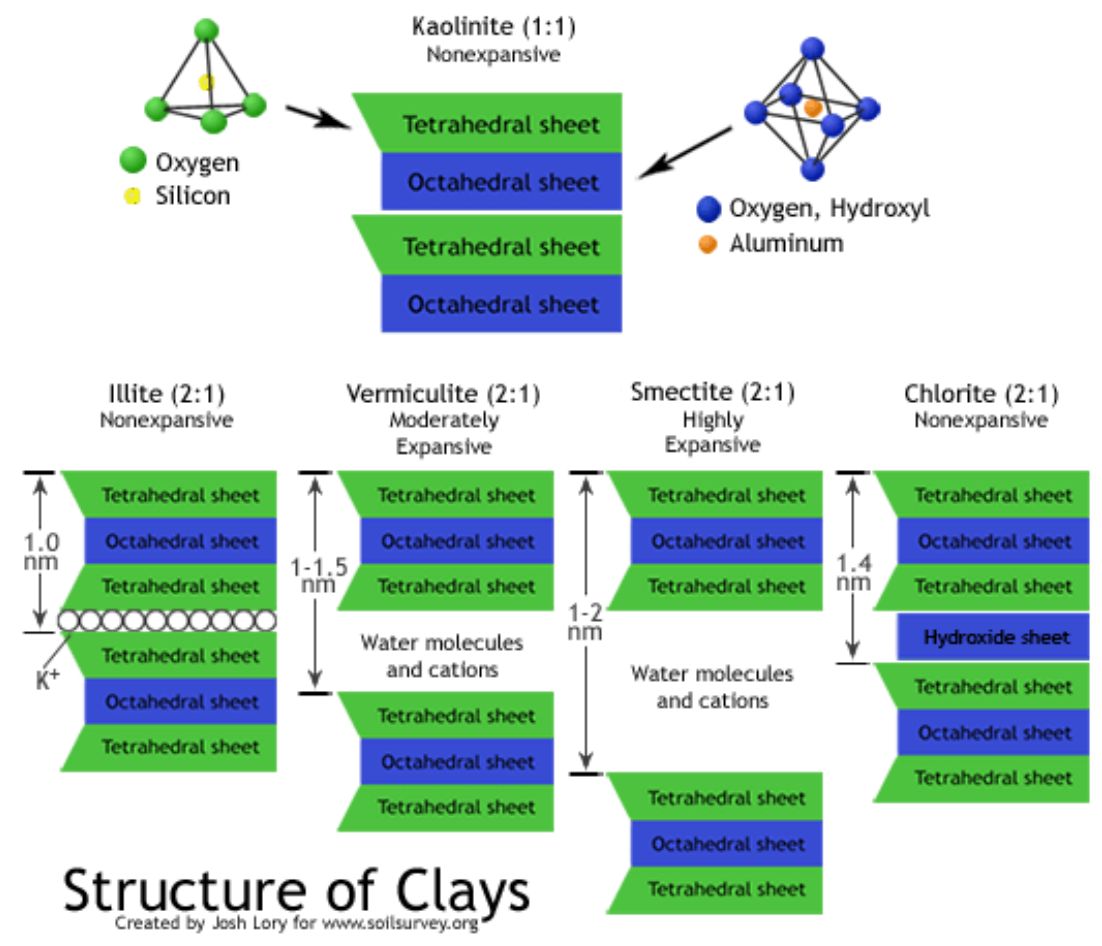

Fig.7: Structure of clays [35], [36]

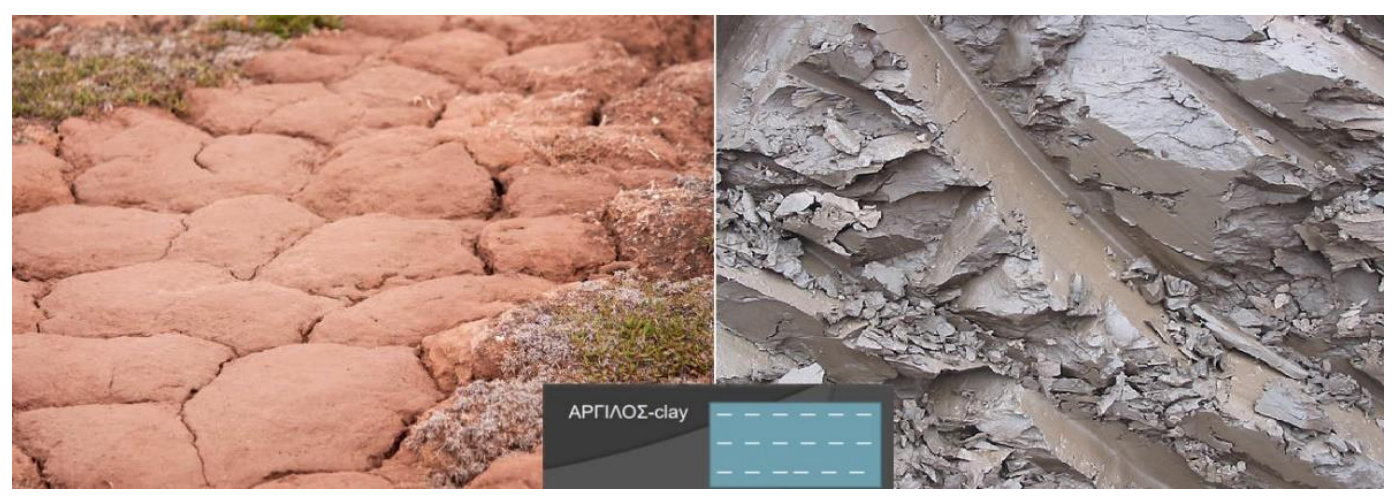

Fig.8: Clay formations [37]

\subsection{Presentation of Triaxial Tests}

This section presents triaxial tests obtained from the thesis or publications of various authors on the three clay minerals. Greater emphasis is placed on the shear behavior of lignite, to which the first author of this work has devoted considerable time since his studies at the National Technical University of Athens (NTUA).

\subsubsection{Marga}

Kalteziotis-Tsiabaos, (2005) [24] recommend that the determination of the residual shear strength of marl specimens should be done using annular shear devices. Koninis-Tika-Kallioglou (2006) [39] point out that, in geotechnical design, the stress of presolidification is considered one of the most important parameters and represents a yield stress of soil, which distinguishes the elastic from its plastic behavior. At the same time, they presented -among other things- triaxial CU tests that were carried out in the Soil Engineering Laboratory of Aristoteles University of Thessaloniki on Marly soils from Mavropigi, Kozani. The soils came from a depth ranging from 11 up to $95 \mathrm{~m}$ and were hypersolidified clays or silt, with an initial pore index between 0.751 and 1.677, a plasticity index between $17.8 \%$ and $34.3 \%$ and a carbonate content greater than $30 \%$.

The authors concluded that apart from the loading history, the structure of the Marly soils has also a significant effect on their behaviour. I. Lazaridis (2014) [40] presented eight triaxial CU tests performed in the NTUA Laboratory, on marly soils at the Isthmus of Corinth area. This material was detached from the Isthmus canal about $1 \mathrm{~m}$ above sea level. In the laboratory (where natural and fermented specimens were tested) it was found that the material had a moisture limit, ML, 30\%, along with a 
plasticity limit, PL, 24\%, characterized on the basis of the Casagrande map as a material of low plasticity. According to the granulometric analysis, the Corinthian marl proved to be a well-graded sludge, with a small percentage of clay material $(8 \%)$. As for the one-dimensional compression behaviour of the marl, the behaviour of the kneaded material does not follow the Burland typical clay response and the compression and swelling curves depend on the initial mixing moisture content. (Lazaridis 2014) [40].

\subsubsection{Kaolinite}

I. Kourelis (2016) [41] under the supervision of Professor Georgianou (NTUA Laboratory) performed 19 triaxial CU tests on kaolinite samples with $\mathrm{OCR}=1$. The kaolinite used is a low plasticity clay. Specifically, the water limit was calculated to $\mathrm{WL}=47 \%$ and the plasticity index PI $=12$. Regarding the granulometry of the material, $72 \%$ of the particles belong to the clay spectrum, while the remaining $28 \%$ to the sludge spectrum. The unit weight of the granules was determined Gs $=2.61$ $\mathrm{gr} / \mathrm{cm}^{3}$, which verifies the corresponding unit weight of kaolinite specimens used in a series of experiments at Imperial College. Regarding the behavior of kaolinite in one-dimensional compression, the response of the fermented material does not follow the behavior proposed by Burland for the fermented clays.

N. Alamanis (1991) [42] in a series of simulations performed at the Ecole Centrale Paris under the supervision of Professor J. Biarez compared the experimental stresses - strain curves of isotropically consolidated kaolinite specimens (from the dissertation of I. Zervogiannis) [43] with the corresponding ones that resulted through the SP5 software application [44], based exactly on the hyperbolic law of Duncan. The samples were consolidated with lateral pressures of $0.4,0.6,0.8$ $\mathrm{MPa}$ while the values of the pore index ranged from 1.1 to 0.812 .

\subsubsection{Lignite}

To investigate the shear strength of Ptolemaida lignite, Alamanis-Mantzouranis (1987) [11] performed (NTUA Civil Engineering Laboratory) triaxial compression tests (CU). The process was realized under various loading conditions and the results have shown that the material behaved in nearly the same way as the clays, nevertheless with minor deviations. For the research, samples of lignite were used, taken from the Northern Area of the Main Field of the Ptolemaida Lignite Mine. Furthermore, the average value of its water content was of the order of $150 \%$ with a drying level at $60{ }^{\circ} \mathrm{C}$, while other samples, presenting a humidity of $159.50 \%$, had a drying level at $105^{\circ} \mathrm{C}$. A period of four to five days at $60^{\circ} \mathrm{C}$, was necessary to achieve a stable, dry weight, while this period was reduced to one or two days at $105^{\circ} \mathrm{C}$. The percentage in organics, burned at $550{ }^{\circ} \mathrm{C}$, was found to be $86 \%$ while the corresponding burned at $775{ }^{\circ} \mathrm{C}$ was estimated at $88.5 \%$. Its liquid weight is $1,165 \mathrm{gr} / \mathrm{cm}^{3}$. The preconsolidation pressure, reaching the order of 20 $\mathrm{kg} / \mathrm{cm}^{2}$, was defined by Casagrande. Hasapis Kazantzis in their dissertation (1986) on Ptolemaida lignites state that the physical characteristics of these lignites are: Liquid effect weight $1,155 \mathrm{gr} / \mathrm{cm}^{3}$, Organic percentage $75-81 \%$, Average water content $144.62 \%$ with drying at $60{ }^{\circ} \mathrm{C}$ and $153.88 \%$ at 105 ${ }^{\circ} \mathrm{C}$ respectively.

For the shear strength determination of the Megaloupolis lignites, Professor A.G. Anagnostopoulos (1980) [45], performed triaxial CU tests with simultaneous measurement of pore pressure. The high level of pressure was at 55-79\% of the lateral one. These tests were used to determine the Mohr strength envelopes for effective and total stresses, the cohesion and in friction angle. It is generally concluded that the lignite material of Megalopolis behaves like preloaded clay material for the cases of soil engineering and foundations.

\subsubsection{Clay}

Aik. Prousanidou (2012) [46] carried out three-axis tests on clay material from the valley of the Sperchios river in the area of Lamia. The samples were obtained from a depth excavation $3 \mathrm{~m}$ and transferred to the Soil Engineering Laboratory of NTUA. In the laboratory it was found that the material had a water limit WL, $57 \%$, a plasticity limit, PL $32 \%$ and a plasticity index, PI 25\%, while the specific gravity of its solid granules was specified to $\mathrm{Gs}=2.61 \mathrm{gr} / \mathrm{cm}^{3}$. From the Casagrande diagram it appeared that the clay material of Lamia is of high plasticity.

Milaković and Szavits-Nossan (2014) [47] predicted the deformations of soil on a short and long-term basis. They used a numerical soil model which, in that period, was widely applicable. The model described accurately the results of triaxial tests, along with the procedures used to determine the soil parameters. The test results, in the form of data, were entered into constitutional equations of the HS model, after which, through a computational procedure, the sampling depth parameters, corresponding to the chosen soil (London clay, Zagreb clay) were obtained. Through the Soil Test program, a series of Standard soil behaviour curves were then obtained, which, numerically, simulates the tests in the Lab. The data obtained from these curves were then compared with the corresponding original test results. 


\subsection{Results Obtained from the Experimental Investigation}

\subsubsection{Marga}
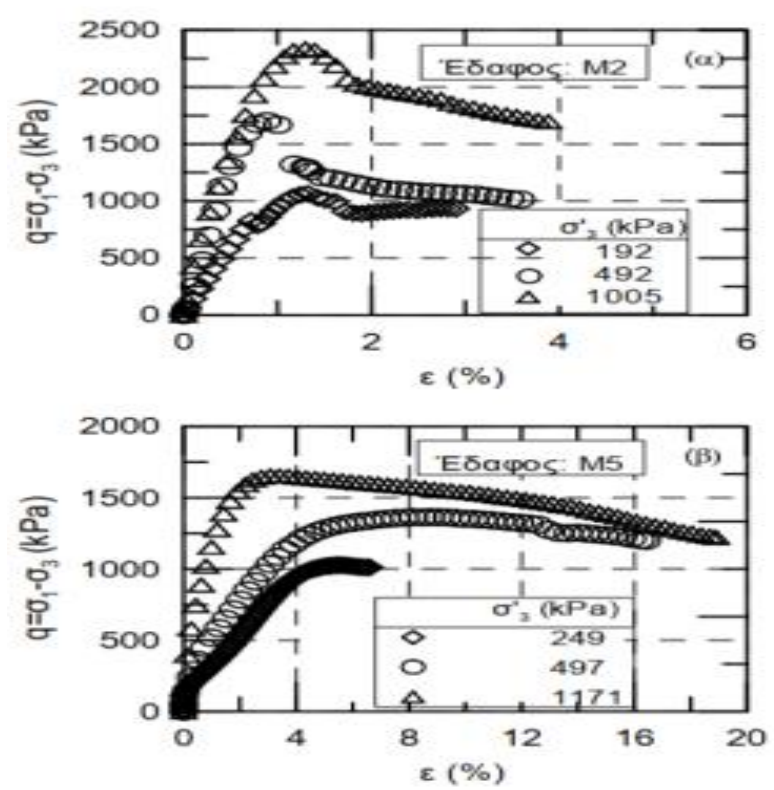

The results obtained from the above-mentioned tests, are depicted in this section, according to the category of clay minerals.

Fig.9: Results of triaxial tests CU for soils M2, M5, M6 and M7 (Koninis-Tika-Kallioglou, 2006)

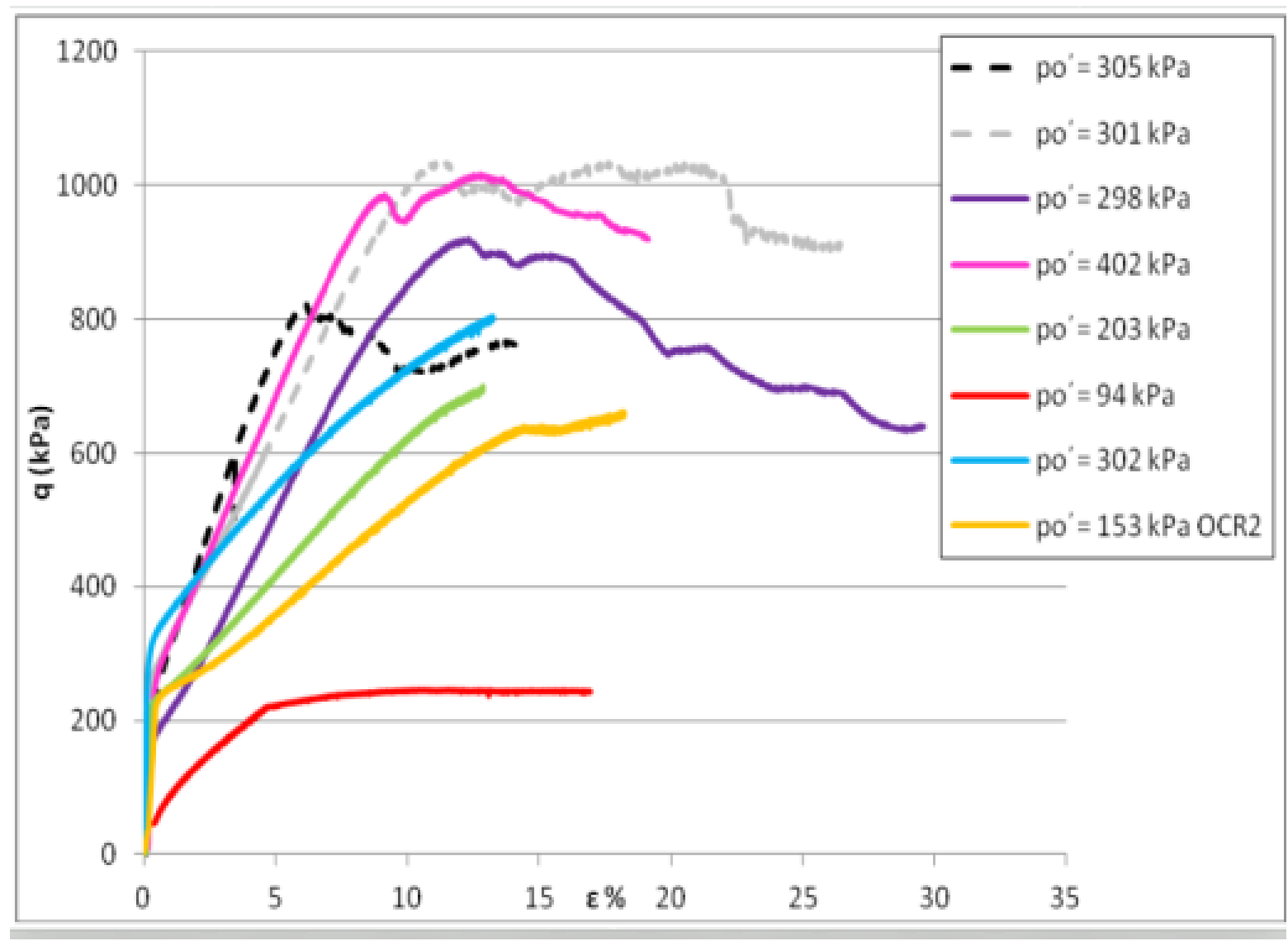

Fig.10: Diagram of deviatoric stress q - axial deformation $\varepsilon \%$, for all CU drainage tests performed. (Lazaridis, 2014) 


\subsubsection{Kaolinite}

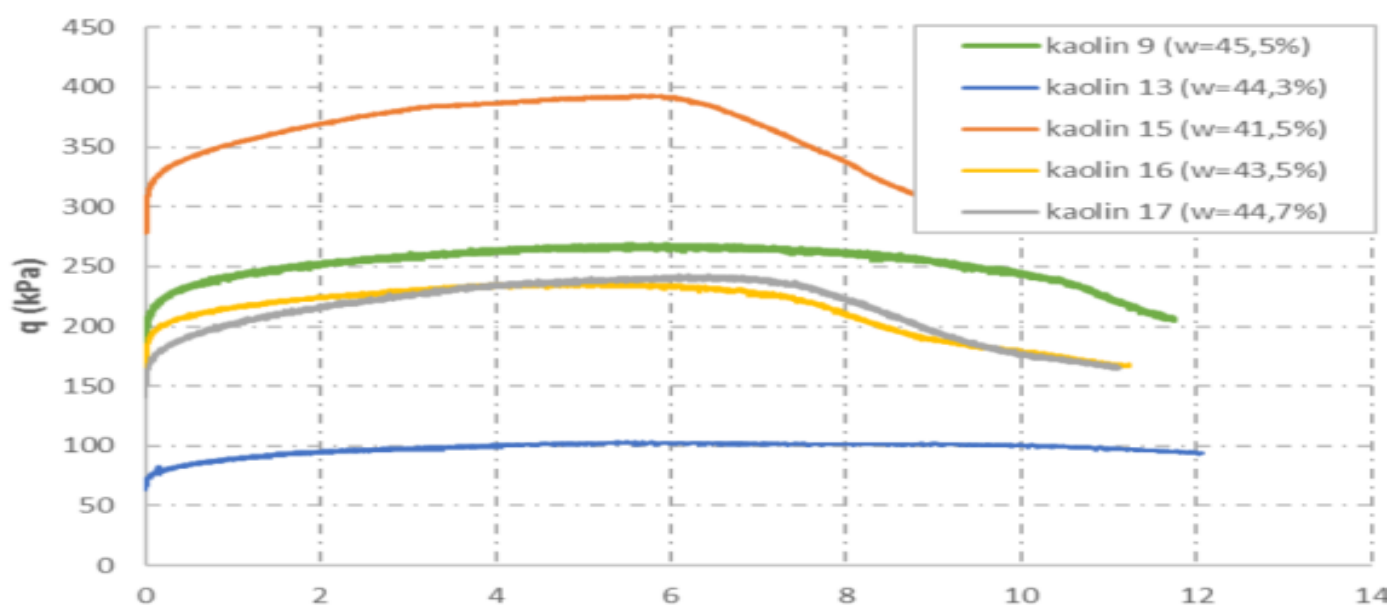

Fig.11: Variation of deviatoric stress q, with respect to the axial strain for 5 specimens consolidated at different average active stresses. (Kourelis, 2016)
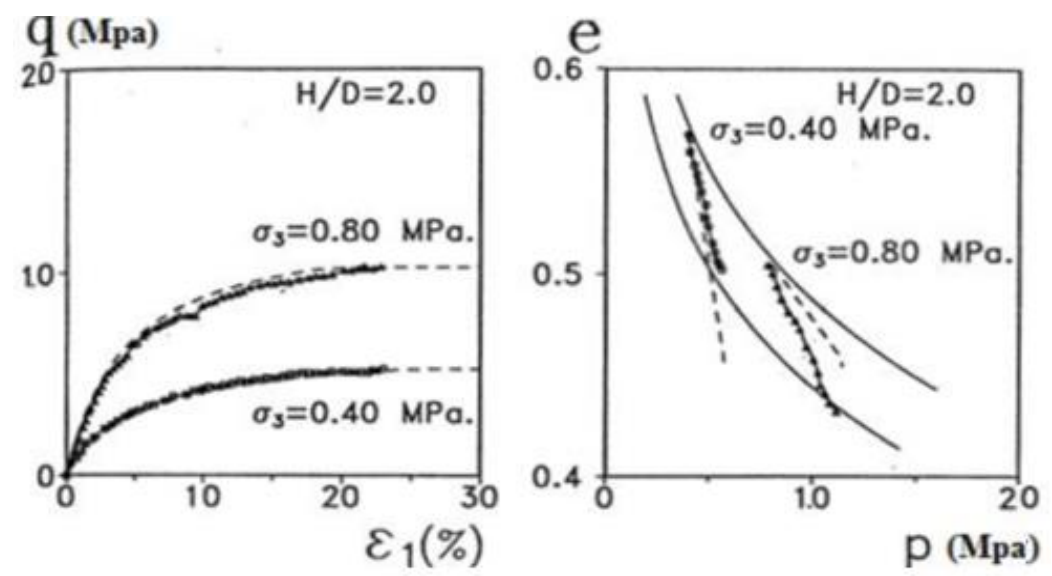

Fig.12: Curves q-eps, e-logp for kaoline N.C (Alamanis, 1990 E.C.P)

\subsubsection{Lignite}

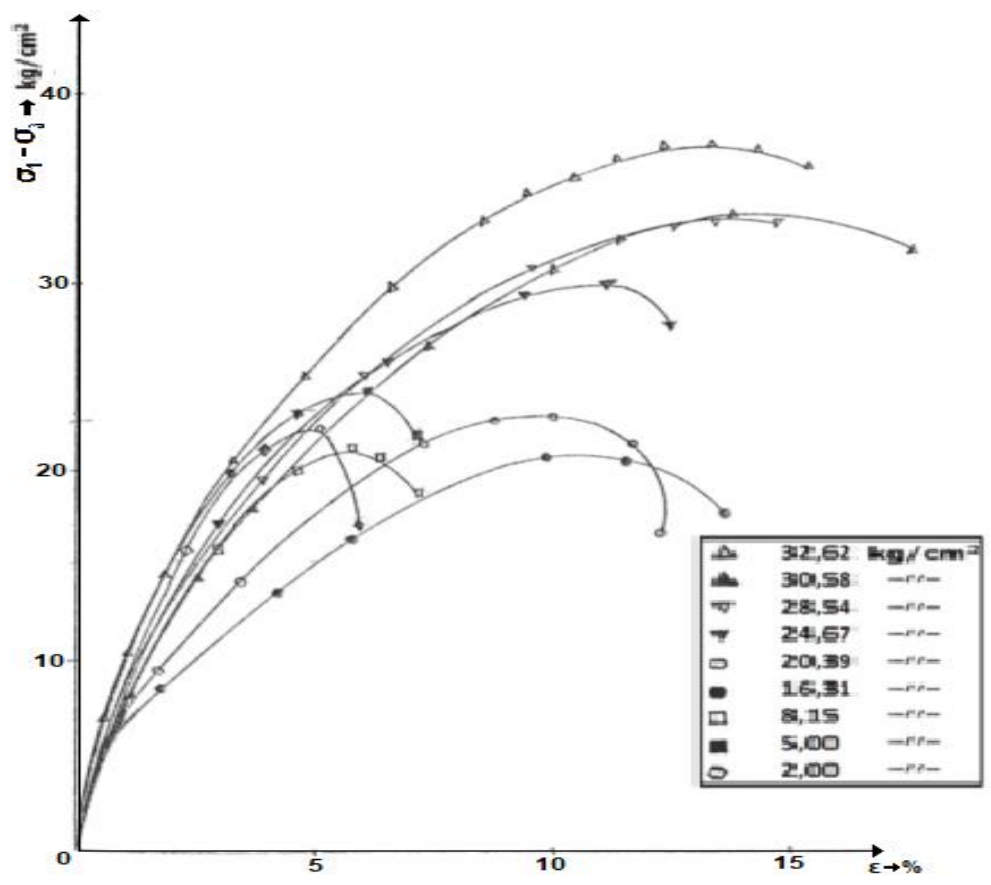

Fig.13: Variaton of the deviatoric stresses with the deformation after three-axis CU tests in the lignite material of Ptolemaida. (Alamanis-Mantzouranis, 1987 NTUA) 


\subsubsection{Clay}

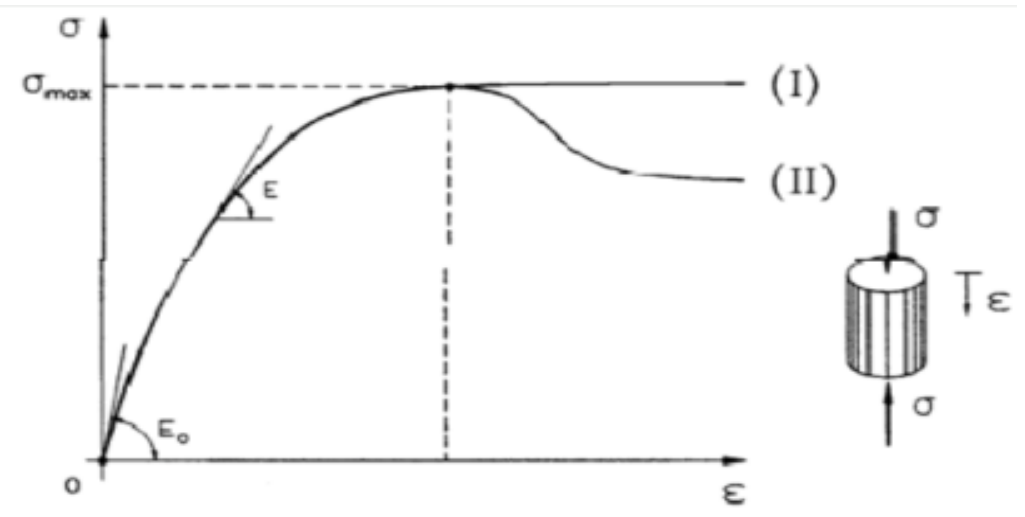

Fig.14: Typical stress-strain curve of uniaxial load of a cylindrical clay test specimen. [11]

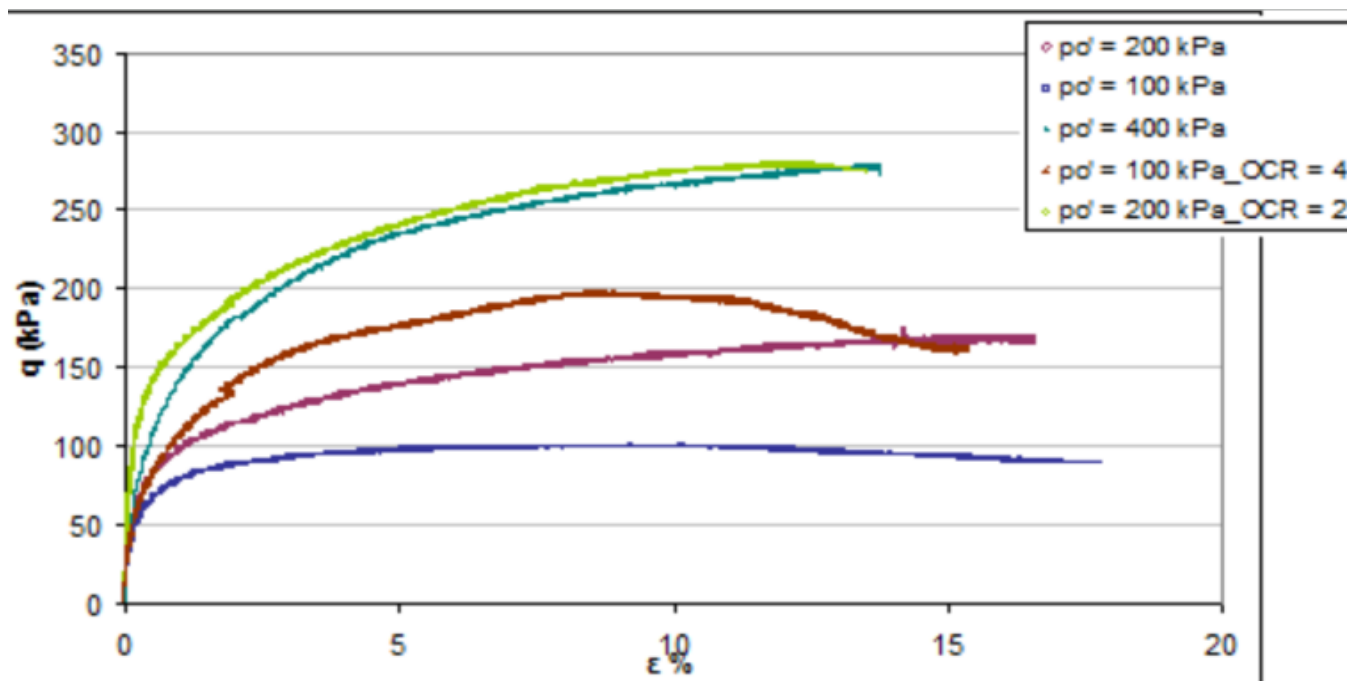

Fig.15: Stress-strain curves from unstructured triaxial CU tests on the clay material of Lamia, (Prousanidou, 2012). [46]

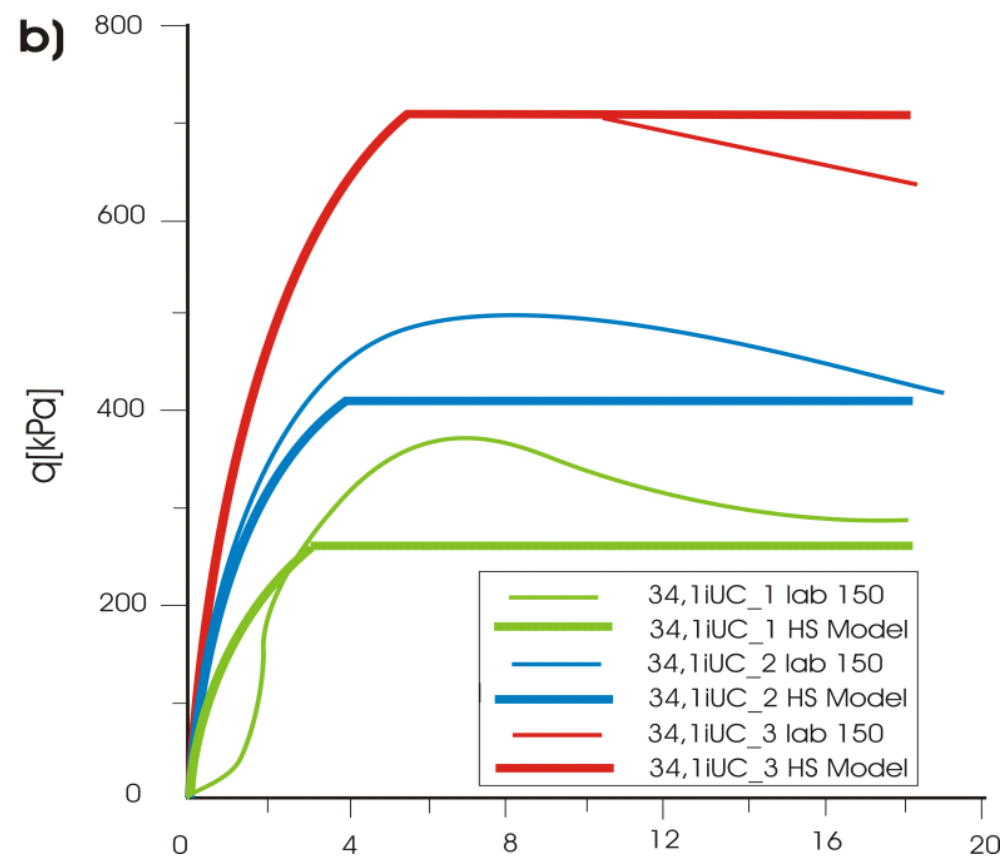

Fig.16: Simulation of volume undrained tests of Zagreb clays, for the HS model: $\varepsilon 1$-q curve for Zagreb clay. [47] 


\section{Comparison of Triaxial Test Results} This section presents the aggregate results of the triaxial tests to which the aforementioned clay minerals were subjected. An attempt is also made to compare their mechanical behavior with that of clay, from which useful conclusions are drawn.

The authors consider that it would be very useful to continue the above research in sandy or gravelly soils, especially in the area of small deformations located in the linear section of the elastic area.

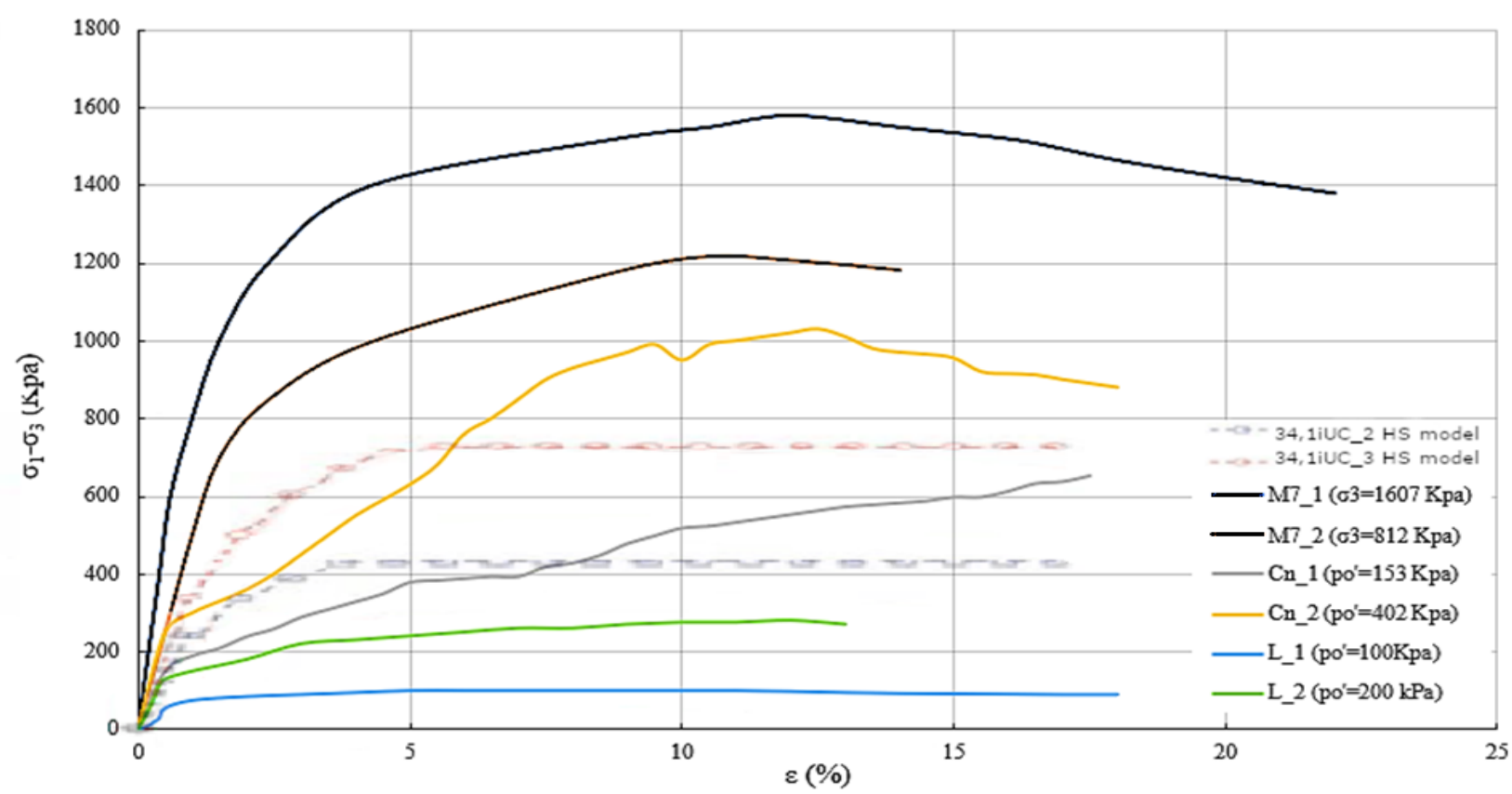

Fig.17: Comparison of marl and clay mechanical behavior: Variation of deviatoric stress with axial stain.

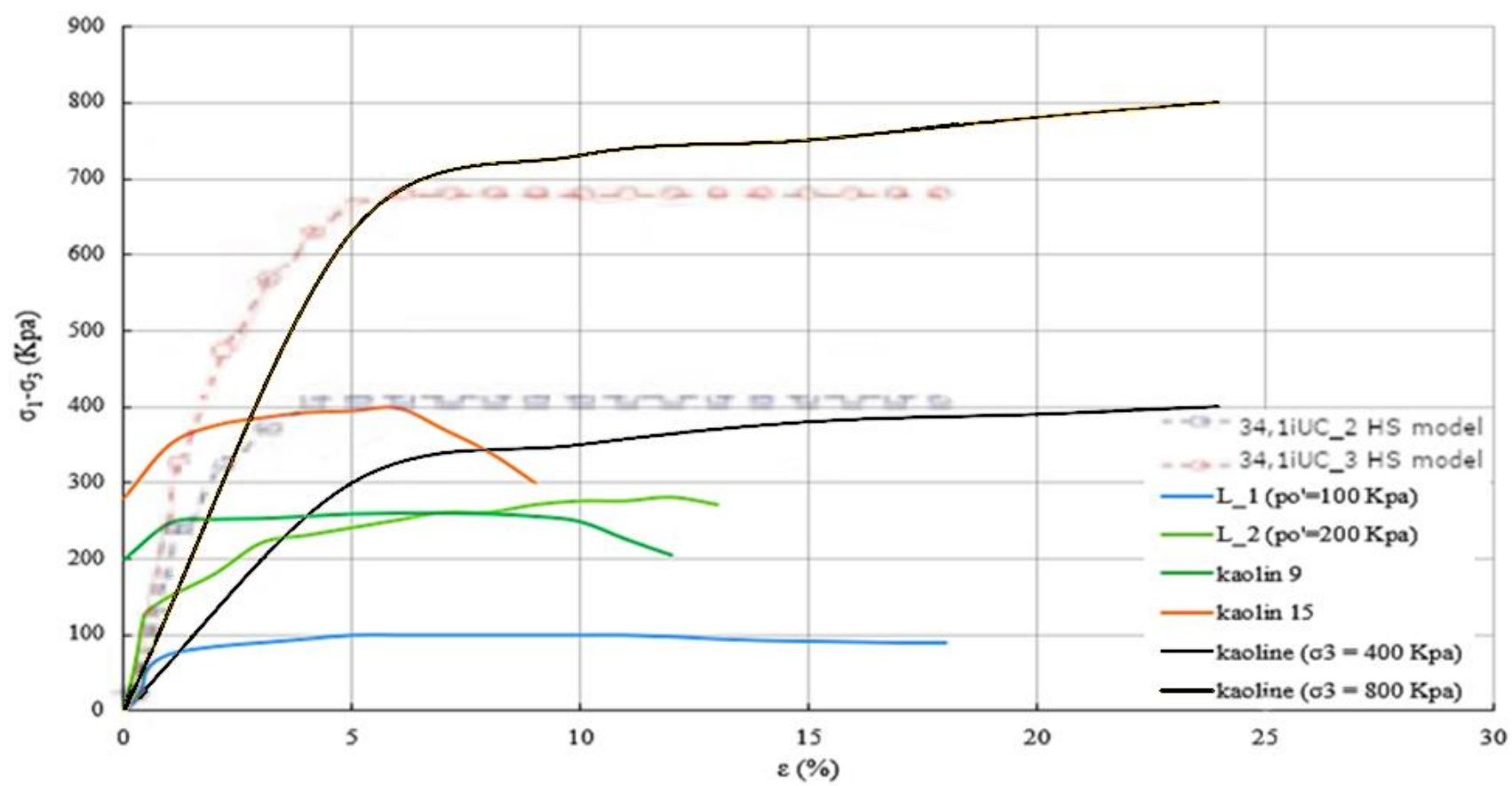

Fig.18: Comparison of mechanical behavior for kaolinite and clay: variation of deviatoric stress versus deformation. 


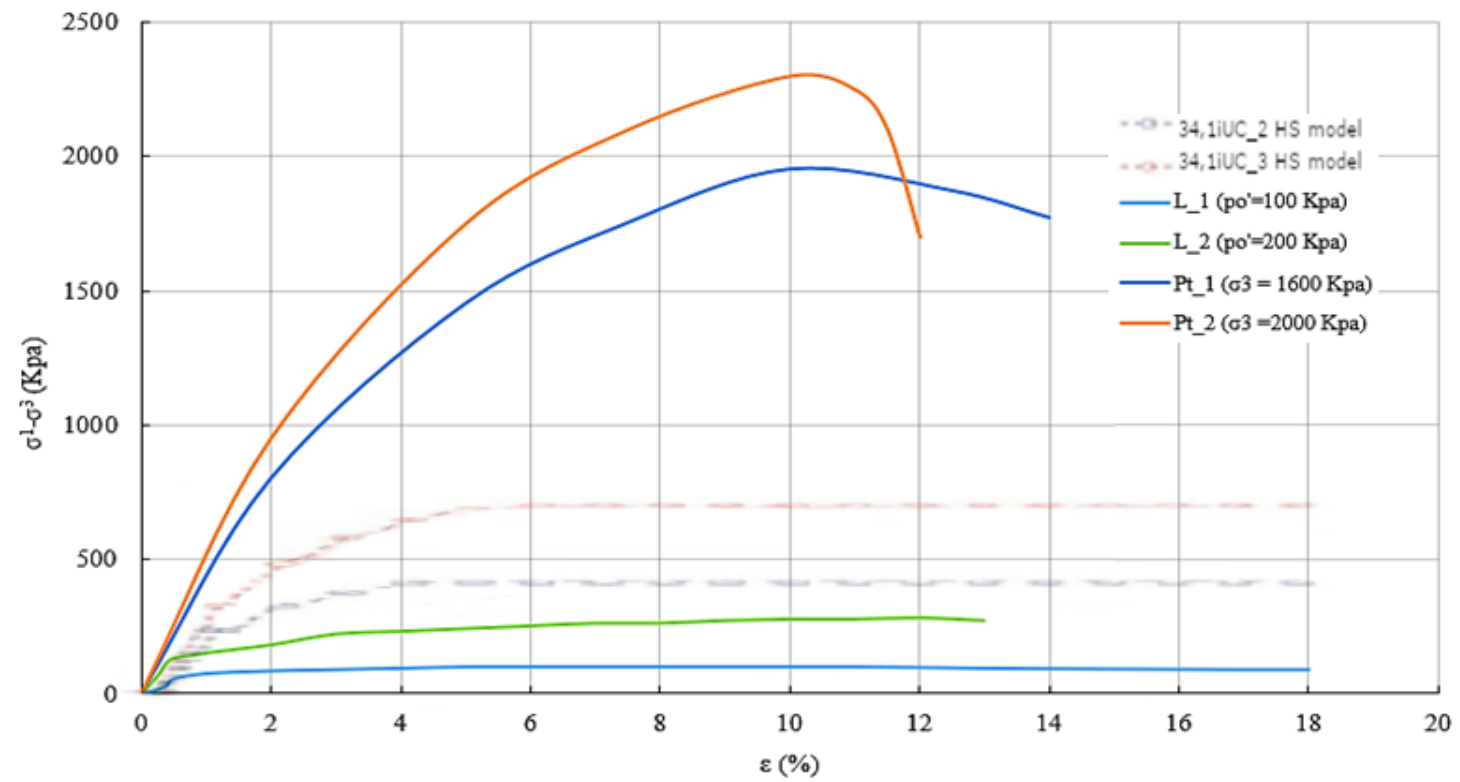

Fig.19: Comparison of mechanical behavior of lignite and clay: Variation of deviatoric stress with axial stain.

\section{Conclusions}

The aim of the authors is to compare the mechanical strength of marl, kaolinite and lignite with that of clay. A really effective way used internationally, is to compare the stress-strain diagrams of each material with that of clay. The shape of these diagrams and the presentation of the $\sigma-\varepsilon$ curves in the same figure, enable the reader to have an excellent picture of the mechanical behavior of each of the aforementioned materials in relation to that of clay.

\subsection{Marl}

The marl coming from the isthmus of Corinth, in its re-fermented form, behaves according to the principles of critical state theory with a critical shear strength angle, $\varphi_{\text {cr }}^{\prime}=31.42^{\circ}$, a constant of critical state, $\mathrm{M}=1.50$, and a Hvorslev shear strength angle, $\varphi=31.4^{\circ}$ (Lazaridis, 2016). Initially, in the above figure 16, one can observe that the lateral stresses for the clay consolidation are much smaller than those of the marl material of Mavropigi and Corinth. However, from the comparison of the mechanical behavior between marl and clay (Fig. 17), the similarity of two materials is obvious, in both preloaded and normal consolidated samples, although the behavior of marl in one-dimensional compression according to Lazaridis does not follow the response of typical Burland clays.

\subsection{Kaolinite}

Kaolinite, in its disturbed form behaves according to principles of critical state theory, with a critical shear strength angle $\varphi^{\prime}=20,52^{\circ}$ for the triaxial compression, while for the corresponding tensile state, $\varphi^{\prime}=29,93^{\circ}$. The specimens fail on the critical- line state regardless of the path of effective stresses that follow, while the deviatoric stress remains constant at its maximum value until the failure of specimen. All normal Consolidated specimens during triaxial compression under Undrained conditions (CU tests) show a tendency to shrink, like the corresponding of clays. (Kourelis, 2016).

N. Alamanis (ECP, 1991), in an effort to evaluate the Duncan's hyperbolic law, used the SP5 software that follows this law and in fact describes the shear attitude of clays. The experimentally obtained curves, using other software, were superimposed on the corresponding curves through the SP5, in order to make the comparison and therefore strengthen the validation of the law. The comparison concerns the parameter values for the soil type (Kaolinite), resulted from the two cases (SP5 and experiment), which, in fact do not differ significantly, with respect to the different values that the initial tangent modulus acquires, as related to the confinement (lateral) pressure and the change of the modulus deformation in volume.

The fact that there is an obvious similarity of the mechanical behaviour between the normal consolidated specimens of the two materials, kaolinite and clay, depicted in Fig. 18, shows that the findings of the above authors converge.

\subsection{Lignite}

To investigate the shear strength of lignite of Megalopolis (Anagnostopoulos 1980) and Ptolemaida (Alamanis-Mantzouranis, 1987), triaxial compression tests with undrained conditions (CU) were performed. It has been proven that the specimen under the action of different loading conditions show a similar behavior to that of clays. However, some 
minor deviations appear, as referred accordingly in each case. It should be emphasized that, for the total stresses, the preloaded part, is a straight line, with a slope practically equal to zero $\left(\varphi=0^{\circ}\right)$, while, afterwards, it continues to be straight, though presenting a larger slope. In contrast to the clays, the preloaded part is curved in the area of low pressures. The point of intersection of the two straight sections corresponds to the area of the preload pressure, as in the case of clays.

Based on the stress-strain diagrams, the deviatoric stress for the same strain proved to increase with the lateral pressure. Furthermore, the strain at break also increases with the lateral pressure. This observation is reinforced by Ladd "dimensionless" diagrams [48]. In fact, the additional vertical pressure (deviation of stresses) is proportional to the lateral pressure for normal loaded specimens as in the case of clays. After the fracture, there is a continuous increase of the pore pressure for the specimens normal consolidated, while for those which were preload, a not significant decrease was observed, in other words the behaviour was similar to that of the clays. It was also found that for the lignite material, the Terzaghi's consolidation theory holds under the same conditions as it was formulated for clay materials. The same conclusions were reached by Trollope-RosengrenBrown (1965) [49] completing the research on the lignite of Latrobe Valley in the Victoria State of Australia after performing compressibility testing and volume compression tests on new samples of lignite from the Yallourn North, Yallourn and Morwell area. Finally, the qualitative interpretation of the $q-\varepsilon$ diagrams in Fig. 19 shows that the similarity of the mechanical behavior of lignite and clay is obvious.

\section{References:}

[1] Philotheos Lokkas, Emmanouil Papadimitriou, Nikolaos Alamanis, Grigorios Papageorgiou, Dimitrios Christodoulou, and Theodoros Chrisanidis: «Significant Foundation Techniques for Education: A Critical Analysis», Wseas Transactions on Advances in Engineering Education doi: 10.37394/232010.2021.18.2., E-ISSN: 22243410 , Volume 18, 2021, p.p. 7-26.

[2] Nicolaos Alamanis (2017). «Failure of Slopes and Embankments under Static and Seismic Loading». American Scientific Research Journal for Engineering, Technology, and Sciences (ASRJETS) (2017) Volume 35, No 1, p.p. 95126.

[3] Papageorgiou G.P., Alamanis N. and Xafoulis N. (2019). «Acceptable movements of road embankments». Electronic Journal of Structural Engineering. 20(1) 2020 p.p 30-32. Melbourne, Australia.

[4] Alamanis Nikolaos, Zografos Christos, Papageorgiou Grigorios, Xafoulis Nikolaos and
Chouliaras Ioannis (2020). "Risk of retaining systems for deep excavations in urban road infrastructure with respect to work staff perception». International Journal of Scientific \& Technology Research, Vol. 9, Issue 2, p.p. 4168-4175 February 2020, ISSN 2277-8616.

[5] Dimos Zachos. Georgios Bakalis Konstantinos Bakalis, Nikolaos Alamanis Grigorios Papageorgiou - Nikolaos Xafoulis (2021). "A methodology for selecting the required cross- $^{-}$section of a self- supporting retaining bulkhead, on a vertical excavation front, of an energy conduit passage trench". Energy Systems, Springer https://doi.org/10.1007/s12667-021-00429-9.

Received: 3 Jan. 2021 / Accepted: 20 February 2021 / Published on line: 06 March 2021, (C) Springer-Verlag GmbH Germany.

[6] Alamanis N., Dakoulas P. (2019). "Simulation of random soil properties by the Local Average Subdivision method and engineering applications". Energy Systems, Springer. https://doi.org/10.1007/s12667-019-00362-y.

Print ISSN 1868-3967, Online ISSN1868-3975 p.p 1-21. Received: 6 March 2019 / Accepted: 2 October 2019, Published on line: 07 November 2019, (C) Springer-Verlag GmbH Germany.

[7] Alamanis N., Dakoulas P. (2018). "Effect of spatial variability of soil properties on the stability and permanent seismic displacements of highway slopes". The 17th European Conference on Soil Mechanics and Geotechnical Engineering 1st - 6th September 2019, Reykjavik Iceland. XVII ECSMGE Reykjavik Iceland 2019.

[8] Alamanis N., Dakoulas P. (2021). "Effect of spatial variability of soil properties on permanent seismic displacements of slopes with uniform load." 14th Baltic Sea Geotechnical Conference 18-19 Jan 2021, Helsinki, Finland.

[9] Terzaghi K., (1936) "The stability of natural clay", Proc. 1st Conf. Soil Meeh. Harvard, vol. 1, p. 161.

[10] Scempton A.W., (1954) "The pore pressure coefficients A and B", Geotechnique, vol. 4, No. 4, p.p. $143-147$.

[11] Alamanis N.O., Matzouranis P.N. (1987). Shearing behavior of Ptolemais lignite, Diploma Thesis: National Technical University of Athens, Department of Geotechnical Engineering, Supervisor: A. G. Anagnostopoulos, Athens, 1987.

[12] Ladd (1971) "Strength parameters and stressstrain behaviour of saturated clays", Research Report R71 - 23, Soils Publications 278, Department of Civil Engineering, M.I.T., p. 280.

[13] Papageorgiou G. 2020. Economic assessment of pavement maintenance and strengthening techniques in view of implementation cost. European Transport \ Trasporti Europei. ISSN 1825-3997. Issue 78, Paper no 5.

[14] Tsiknas A., Athanasopoulou A. and Papageorgiou G. 2020. Evaluation of flexible pavement construction cost according to the design method. Proceedings of the Institution of Civil Engineers (ICE) - Transport, ISSN 0965092X | E-ISSN 1751-7710, ICE Publishing, 
Thomas Telford, London, United Kingdom, Vol. 173, Issue 1, pp. 3-12.

[15] Mouratidis A. and Papageorgiou G. 2010. A Rational Approach for Optimization of Road Upgrading, Canadian Journal of Civil Engineering, ISSN (print): 0315-1468, ISSN (electronic): 1208-6029, NRC Research Press (Canadian Science Publishing), Ottawa, Ont., Volume 37, Number 11, pp. 1462-1470.

[16] Papageorgiou G. 2019. Appraisal of Road Pavement Evaluation Methods. Journal of Engineering Science and Technology Review. ISSN: 1791-2377. Vol. 12, Issue 6, pp. 158-166.

[17] Farsirotou, Evagelia D., Dermissis, Vassilios D., and Soulis, Johannes V. 'Test Case for Bed Morphology Computations'. Journal of Computational Methods in Sciences and Engineering, vol. 7, no. 2, pp. 105-131. DOI: 10.3233/JCM-2007-7203.

[18] Farsirotou, E. \& Xafoulis, N. (2017). An Experimental Study of Local Scour Depth Around Bridge Abutments. International Journal of New Technology and Research (IJNTR), ISSN: 2454-4116, Volume-3, Issue-9, September, pp. 1-10.

[19] Farsirotou, E. \& Xafoulis, N. (2017). Numerical Simulation of Scour Depth Variation Around Vertical Wall Abutments World Journal of Research and Review (WJRR) ISSN:24553956, Volume-5, Issue-6, December, p.p 25-30.

[20] Evangelia Farsirotou, Nikoalos Xafoulis and Spyridon Kotsopoulos (2021). Experimental and numerical simulation of local scouring downstream of sharp-crested weirs in natural rivers. European Water.

[21] Droudakis A.I., Markou I.N., Christodoulou D.N. (2010). "Parametric Investigation of Permeation Grouting Effectiveness in Soils using Microfine Cement Suspensions" 6th Hellenic Conference on Geotechnical and Geoenvironmental Engineering, Volos, 2010

[22] Anagnostopoulos C., Chrysanidis T., Anagnostopoulou M. (2020). Experimental data of cement grouting in coarse soils with different superplasticisers, Data in Brief (DIB), Vol. 30, Article 105612, DOI: https://doi.org/10.1016/j.dib.2020.105612

[23] Nikolaos Alamanis and Ioannis Chouliaras I. (2018). «Improvements to Lose Soil». American Scientific Research Journal for Engineering, Technology, and Sciences (ASRJETS) (2018) Volume 43, No 1, p.p. 190210 .

[24] Kalteziotis N., Tsiambaos G. (2005). Factors affecting the residual shear strength of marls library.tee.gr > digital > m1339 1 kalteziotis.

[25] Tsirambidis A., Papaliaḡas Th. (2001). Mineralogical composition and physical characteristics of marly soils from Heraklion Crete. Bulletin of the Geological Society of Greece, Vol. XXXIV/3, 851-858, 2001. Proceedings of the 9th International Congress, Athens, September 2001.

[26] https://geologyscience.com/rocks/sedimentaryrocks/marl/
[27] Barth, T.F., Correns, C.V. \& Eskola P. (1939). Die Entstehung der Gesteine. Berlin. Julius Springer. $422 \mathrm{pp}$.

[28] Pettijohn F.J. (1957). Sedimentary rocks, 3nd ed. Harper \& Row, New York, 526 pp.

[29] Gioka AP (2014). "Mineralological and geochemical study of sediments from Neogene basins of Crete". Bachelor's thesis. School of Mineral Resources Engineering. Technical University of Crete. Chania, 2014.

[30] Prassa P., Xirouchaki A. (2018). Study of cation adsorption on solid materials of natural origin. Thesis Department of Natural Resources \& Environmental Engineering School of Applied Sciences. TEI of Crete. Chania, 2014.

[31] http://www.orykta.gr/oryktes-protes-yles-tisellados/latomika-orykta/biomihanika-orykta/58kaolinitis

[32] http://amfipolinews.blogspot.com/2018/03/blogpost_534.html

[33] https://www.geologysuperstore.com/productcategory/rocks-minerals-fossils/rockspecimens/sedimentary-rock-specimens

[34] Brown E.T. (1963). "The engineering behaviour of Morwell brown coal", M. Eng.Sc. Thesis, Dept. of Civil Eng. University of Melbourne.

[35] http://soils.misouri.edu/tutorial/images/clay_stru cture/small.png.

[36] Argyraki A., (2013). Course notes, Analytical Geochemistry, Department of Geology and Geoenvironment, Sector of Economic Geology and Geochemistry, EKPA, Athens.

[37] https://www.epicgardening.com/clay-soil/, http://kolibri.teacherinabox.org.au/modules/enwikipedia_for_schoolsstatic/images/467/46758.jpg.htm

[38] Kotrotsiou V., Frantzeskaki E. (2011). Study of the effect of the fermentation phenomenon on the mechanical properties of clay soils. Thesis. Department of Civil Engineering. TEI of Piraeus, Egaleo, 2011.

[39] Koninis G.E., Tika Th. M., Kallioglou P.A. (2006). Correlation Between the Undrained Shear Strength and Preconsolidation Pressure for Marly Soils. 5th Panhellenic Conference on Geotechnical \& Geoenvironmental Engineering, TEE, Xanthi, 31 / 5 - 2 / 6/2006.

[40] Lazaridis I. (2014). Mechanical behavior of the Marga of Isthmus of Corinth. Bachelor's thesis. School of Civil Engineering. Department of Geotechnics, NTUA, Athens, 2014.

[41] Kourelis I. (2016). Triaxial tests on anisotropically consolidated kaolin. Bachelor's thesis. School of Civil Engineering. Department of Geotechnics, NTUA, Athens, 2016.42.

[42] Alamanis N. (1991). "Hyperbolic Law of Duncan. Comparison between SP5 and experience." Thesis D.E.A., Ecole Centrale, Paris 1991.

[43] Zervoyanis Ch. (1982). "Synthetic study of the mechanical properties of saturated clays and sands on an oedometric and triaxial path of revolution". Thesis ECP 1982.

[44] Duncan J.M. and Wong K.S. (1981). "SP5: a computer program for the evaluation of hyperbolic stress - strain parameters" 
Department of civil engineering, University of California Berkeley, 1981.

[45] Anagnostopoulos AG, (1980). "Soil-technical behavior of the Lignites of Megalopolis", Dissertation on subordination, S.C.E., NTUA, Athens (1980).

[46] Prousanidou AI (2012). Mechanical behavior of Lamia clay. Bachelor's thesis. School of Civil Engineering. Sector of Geotechnics, NTUA, Athens, 2012.

[47] Milaković D., Szavits-Nossan A. (2014). Ground settlement induced by tunnel boring in stiff clay Zagreb. Gradevinar 66 (2014) 6, 503512. DOI: $10.14256 / \mathrm{JCE} .1044 .2014$

[48] Ladd C.C. \& Foot R. (1974). "New design procedures for stability of soft clays", ASCE Journal of Geotechnical Engineering Division, Vol. 100, No. GT7, pp. 763-786.

[49] Trollope D.H, Rosengren K.J., Brown E.T. (1965). The mechanics of brown coal, Geotechnique, vol.15, No.4, p.p. 363-386.

[50] Fattah M.Y., Salman F.A and Nareeman B.J. (2020). "Numerical Simulation of Triaxial Test in Clayey Soil Using Different Constitutive Relations" Advanced Materials Research Vols. 243-249 (2011) pp 29732977

[51] Augustesen A.H., Steenfelt J.S., Goth J.N. (2016). "Triaxial testing of overconsolidated, low plasticity clay till" NGM 2016 Reykjavik Proceedings of the 17th Nordic Geotechnical Meeting Challenges in Nordic Geotechnic 25th 28th of May 2016.

\section{Contribution of Individual Authors to the Creation of a Scientific Article (Ghostwriting Policy)}

N. Alamanis had the idea of writing this article since for many years he wanted to compare the results of his own work with the results of other authors to make more understandable and complete the mechanical behavior of clay minerals.

Ph. Lokkas organized the research and the methodology of the paper and actively participated in both the translation and the submission of the text. In fact, together with N. Alamanis, carried out the comparison and simulation of triaxial tests.

Th. Chrysanidis helped in the collection of material but also in the translation of the text.

D. Christodoulou presented previous experimental and analytical studies.

E. Paschalis helped in the creation of the graphs.

It should be noted, however, that all the authors reviewed the paper and came to the interesting conclusions of the above work.

Sources of Funding for Research Presented in a Scientific Article or Scientific Article Itself

There were not potential sources of funding.
Creative Commons Attribution License 4.0 (Attribution 4.0 International, CC BY 4.0)

This article is published under the terms of the Creative Commons Attribution License 4.0 https://creativecommons.org/licenses/by/4.0/deed.en US 